\title{
20. A Research Framework for Operationalizing Measures of Enterprise Integration
}

\author{
Ronald E. Giachetti, ${ }^{1}$ Paula Hernandez, ${ }^{1}$ Alba Nunez and Duane P Truex ${ }^{2}$ \\ 1 Industrial \& Systems Engineering, Florida International University, \\ Miami, FL Email:giachetr@fiu.edu \\ 2 Computer and Information Systems, Georgia State University, Atlanta, GA
}

This paper develops a research framework to investigate measures of enterprise integration. In our view the tem enterprise integration is an umbrella term that incorporates what we term integration types. The integration types are connectivity, information sharing, interoperability, coordination, and alignment. To determine which technology andior enterprise integration method is best in a given situation we betieve measures of integration are needed and must be grounded in enpirical findings.

\section{INTRODUCTION}

This paper proposes a research framework to help answer two questions that arise when enterprises attempt to integrate technical and social processes and systems: First, what type of integration is needed? and second, what social and technical systems should be integrated for a particular business problem?

To answer these questions we develop a research framework to operationalize five integration types. The operationalization involves a definition of the constructs, relationships between those constructs, and how to measure them. The way in which we state the research questions, i.e. what type of integration indicates our presumptions concerning the solution. We assume a contingency-based view of the enterprise integration problem; i.e. we believe the best integration type is dependent on the particular business problem being addressed.

\subsection{Background}

We define an enterprise as an organization composed of interdependent resources (people, technology, infrastructure and machines) which must coordinate their functions and share information in order to achieve common enterprise goals. We refer to this as the enterprise integration problem rather than as simply coordination for two reasons. First, integration is a broad term that includes many integration types of which coordination is a single type. Second, enterprise integration conveys that the integration problem is not just a technical problem to be solved with IT, but also a social or organizational problem. Crucial issues facing enterprise systems managers and integrators are how much to integrate, what to integrate and how to achieve this coordination. Historically, organizational work systems were designed, built, and optimized to solve the local needs. There is little regard for how the local 
system would fit into the entire enterprise. These local systems utilize various data representation formats, have different data semantics, are built using different programming languages, employ different work process models and are launched on various hardware platforms. Management and information theorists have long understood the need for greater inter and intra organizational interaction such that the problem of how to integrate these heterogeneous systems has been a significant research agenda for more than twenty-five years (Petrie 1992; Patankar and Adiga 1995; Vernadat 1996; Vernadat 2002).

It has been established and is generally accepted that integration leads to improved enterprise performance (Armistead and Mapes 1993; Frohlich and Westbrook 2001; Brunnermeier and Martin 2002). Many researchers take this relationship as the starting point to develop and specify solutions to the integration problem. However, in a review of over 150 integration studies we find differing definitions of integration (Giachetti 2004). In a study commissioned by NIST, Brunnermeier and Martin (2002) estimate that poor interoperability between systems in the US automotive supply chain cost one billion dollar annually. The study was limited to one aspect of integration, interoperability between applications and did not consider other types of integration. Others have focused solely on information sharing (Lee and Whang 1998) or coordination of decisions (Malone and Crowston 1994). If there are many types of integration then the question remains, what is the most appropriate type of integration for a particular business situation? We have been unable to find an answer in the literature to this question.

One solution widely suggested is to install a single monolithic system, i.e. an enterprise resource planning (ERP) system, as a solution to all integration problems. Today, almost every Fortune 500 company has implemented an ERP system. ERP is a single vendor solution and thus interoperability problems are in theory avoided. In practice, while ERP replaces the many independent information systems companies operated (e.g. accounting, billing, order entry, and so forth); these same companies have found they still must maintain other applications, which must be integrated with the ERP system (Themistocleous et al. 2001). Moreover, the complexity of ERP implementations means that many companies fail to realize the promised benefits of integration (Kumar and Van Hillesgersberg 2000). One reading of the literature suggests that using ERP systems to solve the integration problem is not a silver bullet. An alternative strategy is to have decentralized and highly distributed systems. These distributed systems are integrated via middleware or enterprise application integration (EAI) (Linthicum 2000).

In summary, enterprise integration (EI) has been shown to contribute to higher levels of performance of enterprise systems. However, studies show that EI is poorly understood and poorly applied in industry. EI research is needed to lead to a better understanding of integration and how it can be achieved. It seems advances can be made by considering the many different types of integration. Not all integration types are appropriate for every business situation, and research is needed to understand when and how to use each integration type.

\section{ENTERPRISE INTEGRATION}

There is a significant body of literature on enterprise modelling and enterprise integration. A prevalent research approach is the development of enterprise reference architectures that describe the enterprise from many different viewpoints 
in order to deal with the complexity of the enterprise system. Reference architectures that have been developed include CIMOSA (AMICE 1993), GRAI (Doumeingts et al. 1987), PERA (Williams 1994), and GERAM (Bernus 2001). The reference architectures embody knowledge of what enterprise engineers should analyze and how they should analyze it. The reference architectures decompose the enterprise into different viewpoints and levels of genericity. For example, CIMOSA has four complementary views of function, information, organization, and resources. Whenever you decompose a system the problem is how to integrate or relate the analysis and design done of the subsystems. The reference architectures provide guidance on how to accomplish this. The enterprise modelling research has matured to the point such that we have available validated modelling constructs, a convergence in reference architectures, and ontologies and other developments to formalize the collective enterprise knowledge gained. We believe to move the field forward there is a pressing need for the identification and quantification of the enterprise integration parameters. In other words, identifying constructs that have high impact on enterprise integration and defining measures for those constructs. We believe that measurement is a necessary component to further establishing a science base for enterprise integration.

\section{RESEARCH FRAMEWORK}

The research framework is limited to intra-enterprise integration. Thus, we avoid the issues specific to inter-enterprise integration such as studied in supply chain management. In order to conduct the study the unit of analysis needs to be defined. In an organization integration could be studied at different levels. For example, department level, person to person level, or between systems. We choose the business process as the level of analysis. This choice is in accordance with the underlying concept governing CIMOSA (Vernadat 1996).

The research framework shown in Figure 1 articulates a contingency perspective of enterprise integration. In this model the enterprise will realize positive performance impacts when the enterprise matches or fits the right integration type with the enterprise characteristics. Consequently, the best integration type is contingent on the characteristics of the enterprise to be integrated. In the following subsections each of the constructs are described and then relationships between constructs are proposed.

\subsection{Enterprise Integration Types}

As an initial conceptual model of the enterprise we see a layered framework of related independent activities sharing common goals that, taken as a whole, describe essential aspects of an organization. Some of the layers might be seen as 'technical' elements and others as 'social elements'. Taking a dualistic view separating the technical and social as if they were wholly independent of one another would be a mistake. This is because technologies contain embedded assumption about work practices, cultural values and norms and because social units act in reference to technologies. The social and the technical are intricately interrelated. For instance a data model may be seen as a model of business rules and practices. Similarly, software applications embed values, norms and work practices. Taken independently each of these layers can be seen as a view of the enterprise. We say 
this because each layer models and supports core assumptions about its fit in the hierarchy and a particular type of integration goal.

For the purposes of this analysis we consider five broadly defined subsystems each with its own specific integration issue to be addressed. The levels are termed: network, information, application, work processes, and organizational levels (Giachetti 2004). The enterprise integration types are shown in Figure 2 and each level is described next.

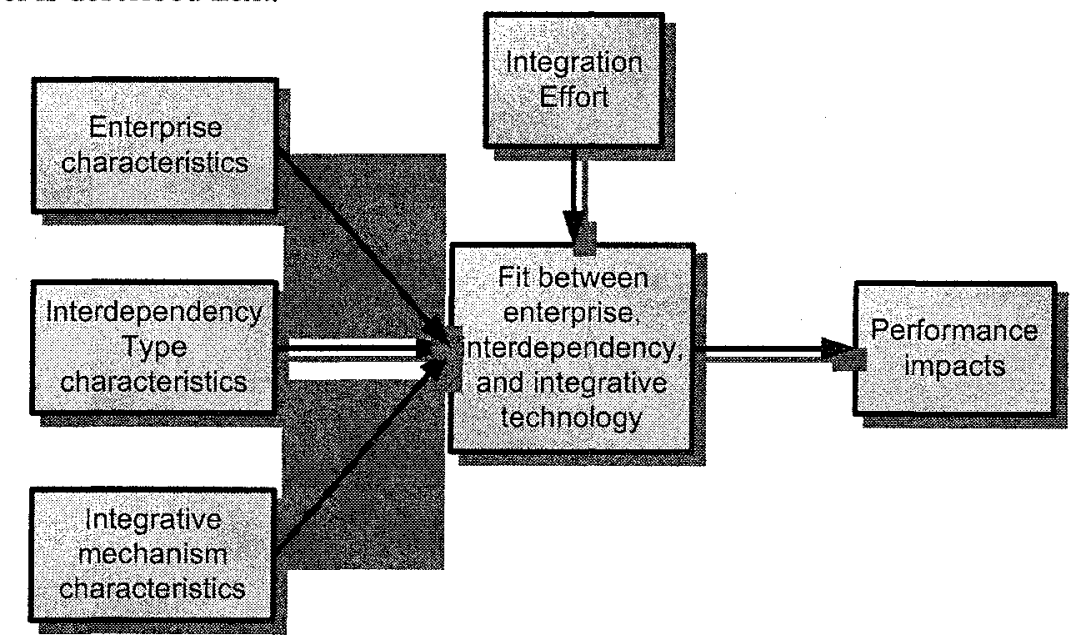

Figure 1. Enterprise integration research framework

\section{Connectivity}

At the network level, the integration issue is the physical heterogeneity of the hardware, machines, devices, and their operating systems found in a physical network. The integration goal at the network level is connectivity defined as the linkages between systems, applications, and modules.

\section{Data Sharing}

Data sharing is the ability of one organizational subunit to understand and use the data originating from another subunit. There are two components of this definition. First, the subunits must exchange data. Second, the data exchanged must be understood by the receiver. This second requirement is harder to satisfy then the first, because semantic differences among units and subunits are still prevalent in many companies.

\section{Interoperability}

The application level, describes the systems used by the business. The integration goal is interoperability, which is the ability of one software application to access/use data generated by another software system. Interoperability of software applications is usually achieved by developing interfaces to a system such as through an application protocol interface (API), with middleware, or with other enterprise application integration (EAI) technologies (Ruh et al. 2000). 


\section{Coordination}

The work process level describes the tasks and the manner and order in which the tasks are conducted in order to produce an output. The problem of task dependencies occurs at this level and the integration issue is called coordination. Coordination has been defined as the "management of the dependencies that arise between business tasks" (Malone and Crowston, 1994). Coordination is achieved by integrating decisions. Mintzberg (1979) defined six broad categories of coordination mechanisms that organizations can use to coordinate their tasks. These are 1) standardization of norms, ideology, and culture,2) standardization of skills, 3)standardization of outputs, 4) standardization of work processes, 5) direct supervision, and 6) mutual adjustment.

\section{Goal Alignment}

The organizational level addresses the way that the three key elements of business strategy, organizational design strategy and information systems strategy must all be aligned with one another. A change in any of these elements requires an adjustment in the others. Thus alignment is the integration task at this level of analysis (Venkatraman and Henderson 1993; Joshi 2003).

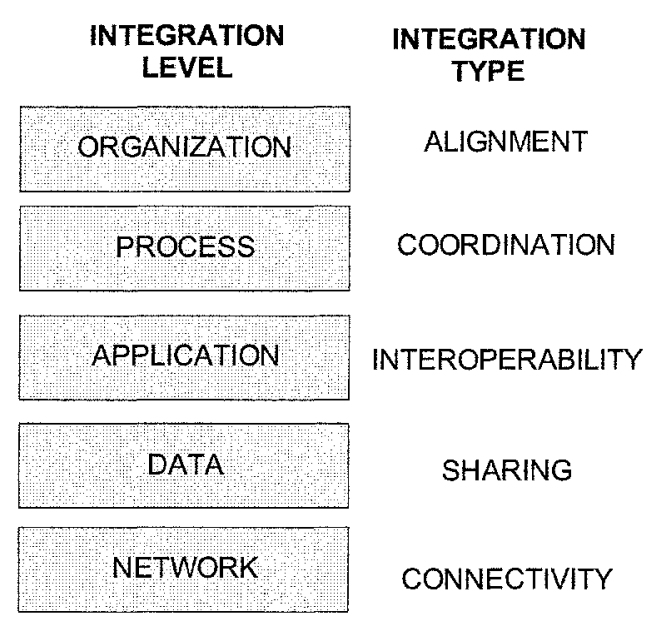

Figure 2. A framework to assess levels of enterprise integration (adapted from Giachetti 2004)

The enterprise integration level assessment framework is intended to unite different perspectives of enterprise integration as can be found in the literature review. For example, middleware approaches focus on interoperability at the application level, database approaches on the data level, and cross-functional teams at the process level. Each integration type will allow for constructions of measures of enterprise integration. Enterprise integration within a single company implies alignment within and between the different levels into a cohesive enterprise system. Interenterprise integration can occur at any level. 


\subsection{Interdependency Characteristics}

In general an interdependency exists when there is any type of flow between people, organizational units, or applications within the enterprise. Flow types are material, information, decision, economic, and resources. Managing interdependencies between tasks and organizational units is viewed as critical to the smooth operation of a business (Crowston 1997; Camarinha-Matos and Pantoja-Lima 2001; Albino et al. 2002).

There are many different types of dependencies and authors have developed taxonomies to categorize and classify them (Malone and Crowston 1994; Whang 1995; Crowston 1997; Kim 2001). Identifying the existence of these interdependencies can be achieved through modelling activities such as data flow diagrams or IDEF0 to capture information flows or the GRAI methodology to capture decision control flows reveals the structural nature of the interdependency. For example, by showing a sequential dependency in which the output of one task is a required input to another task we have identified the existence of a particular type of dependency. What is also needed is a characterization of the strength of that interdependency. Strength of the interdependency has been modelled by the frequency of the communication (Christensen et al. 1996). Another approach is to use psychometric measures and survey participants to obtain a measure of the perceived interdependency (Wybo and Goodhue 1995).

\subsection{Enterprise Characteristics}

The enterprise characteristics may become obstacles to certain integrative type solutions or may facilitate other solutions. The literature on enterprise integration was examined to reveal what important enterprise characteristics impact integration. In this study we study three characteristics: 1) functional differentiation, 2) uncertainty, and 3) task analyzability to understand the nature of enterprise integration. These factors are based on an information processing theoretical view of the organization (Galbraith 1977) and have been utilized in many similar studies (Daft and Lengel 1986; Albino et al. 2002; Koufteros et al. 2002).

\section{Functional Differentiation}

Functional Differentiation is the degree to which different functional units (e.g. design, accounting, finance, and so forth) have different cultural norms, goals, methods, and vocabularies (Lawrence and Lorsch 1967; Daft and Lengel 1986). When functional differentiation is high it can become an obstacle to enterprise integration. Moreover, when functional differentiation is high, some forms of integration, for example data integration may reduce the flexibility individual subunits need to deal with their environment and thus could have a negative impact on performance (Wybo and Goodhue 1995).

A method to measure goal incongruence is by a card sorting method (Christensen et al. 1996). In this approach all the possible goals are individually written on a card. Then each actor sorts the cards according to goal priority. The difference between any two actors selection is a measure of goal incongruence.

\section{Task Uncertainty}

Galbraith (1977) defines uncertainty as the gap between the amount of information required to perform a task and the information already possessed by the 
organization. Galbraith identified factors that contribute to uncertainty at the organization level such as goal diversity and labor diversity. What contributes to the uncertainty is likely industry specific. For example, Flynn and Flynn (1999) identified several additional factors that contribute to uncertainty in the manufacturing enterprises.

To cope with task uncertainty Galbraith identified two general strategies. The first is to reduce the information processing needs of the organization. The second is to increase the information processing capability of the organization. Clearly, integration is one means to implement the second strategy. To increase the information processing capability you can share data (data sharing integration type).

Task uncertainty is usually measured through survey methods (Daft and Lengel 1986; Victor and Blackburn 1987; Rosenzweig et al. 2003). An analytical approach would be to define the information requirements for a task and then to identify what proportion of the information requirements are available locally for the organizational unit to perform the task and the proportion that must be retrieved from other sources.

\section{Task Analyzability}

Task analyzability is whether the task can be managed by a defined set of procedures (Perrow 1967). Tasks that are routine and can be addressed by welldefined procedures are termed analyzable. When tasks are unanalyzable employees use judgement to make decisions. Task analyzability is measured through survey methods (Van de Ven and Delbecq 1974; Rice 1992).

\subsection{Performance Impacts}

Enterprise integration has been found to lead to improved enterprise performance. In the context of the research model performance impact means the integrative type when used in the presence of the enterprise environment and interdependencies will improve some unit level performance measure. For example, improved efficiency, improved effectiveness, improved quality, or other performance measures are possible.

Objective measures are frequently difficult to find at this level of analysis and also to isolate the impact from the integrative type is difficult. The approach taken is to use user evaluations of performance impact. The model of (Goodhue 1996) for measuring user evaluation can be used for this purpose.

\subsection{Integration Effort}

Integration effort is the difficulty level of achieving integration and is measured in terms of cost, time, and amount of resources that must be used in order to achieve the desired integration. Similar to performance, measuring effort is not always straightforward in an organization. A user evaluation of the effort required for integration is potentially the best measurement approach.

\subsection{Relationships}

The model shown in Figure 1 propositions several relationships between the constructs and enterprise performance. The first relation is between functional differentiate and various integration types. 
Proposition \#1: When functional differentiation is high the integration effort required will be high.

Functional differentiation increases when organizational units must specialize to complete their tasks. Highly specialized units develop their own vocabulary which would make data integration more difficult since there would be greater semantic differences between the organizational units. Moreover, applications for highly differentiated organizational units tend to be optimized for local needs. Therefore, it is unlikely their software applications were designed for interoperability. Finally, highly differentiated units will have different goals. Collectively these characteristics would impose the need for greater effort in order to achieve the integration. Additionally, high functional differentiation would suggest the following integrative types would be more effective.

Proposition \#2: In enterprise environments with high functional differentiation integrative strategies that include goal alignment and data sharing would have the greatest performance impacts.

The justification for this proposition is that goal alignment and data sharing are meant to overcome the difficulties associated with functional differentiation. Whereas, achieving interoperability or coordination through the mechanisms identified by Mintzberg (1979) will have less impact in the presence of continued goal and semantic differences.

Proposition \#3: In enterprise environments with high uncertainty integrative strategies that include data sharing and interoperability will have greatest performance impacts.

High uncertainty defined as the absence of information is addressed by increasing information processing capacity. Frequently, the information to complete a task is needed from other organizational units. Consequently, it is expected that integrative technologies that increase information processing capacity such as data sharing and interoperability will have positive impacts on performance.

Proposition \#4: In enterprise environments with low analyzability integrative strategies that include data sharing and interoperability will have minimal performance impacts.

Low analyzability describes tasks that even with additional information the performance of the task is not improved because the decision making relies on judgement and not an analysis of the information available.

Proposition \#5: Interdependency and performance impacts are proportional such that the greater the interdependency the greater the performance impact.

The justification for the last proposition is that when organizational units are interdependent then integrating them leads to increases in efficiency and effectiveness for each unit in performing their tasks. When organizational units how low interdependence then integrating them will have little or no impact on their performance.

\section{CONCLUSION AND FURTHER WORK}

The primary contribution of this paper was to identify important environmental factors that are hypothesized to impact integration technology choice and 
performance. Our model is more specific about the constructs and explicit concerning the relationships than previous research. Approaches to measuring the constructs were identified. The majority of the measures rely on previously validated measuring instruments.

While significant advances have been made in enterprise modelling and understanding enterprise integration there is a lack of measurement. Defining constructs and how to measurement them is at the foundation of developing theory in a field (Wacker 1998). In this paper we presented a contingency-based model of enterprise integration. We identified three classes of constructs: enterprise, interdependency, and integration type. Propositions were formulated to determine the fit between each of these constructs and the overall impact on performance.

The future work is to test the model by collecting data and performing statistical analysis to validate each of the proposed relationships. Work is going forward on using the research framework to understand enterprise integration in the South Florida cruise industry. If strong evidence is found to support both the construct measures and the relationships then we would have achieved a strong theoretical basis for thinking about the impact of various integration types on enterprise performance. It would be possible to build a software tool for computer aided enterprise integration to aid analysts in studying business situations and designing integrative solutions.

\section{Acknowledgments}

The work was partially funded by the National Science Foundation under grant DUE-0220667 and by NASA AMES Research Center under grant NAG2-1612.

\section{REFERENCES}

Albino, V., P. Pontrandolfo, et al. (2002). "Analysis of information flows to enhance the coordination of production processes." International Journal of Production Economics 75: 7-19.

AMICE (1993). CIMOSA: CM Open Systems Architecture. Berlin, SpringerVerlag.

Armistead, C. and J. Mapes (1993). "The impact of supply chain integration on operating performance." Logistics Information Management 6(4): 9-15.

Bernus, P. (2001). "Some thoughts on enterprise modelling." Production Planning \& Control 12(2): 110-118.

Brunnermeier, S. B. and S. A. Martin (2002). "Interoperability costs in the US automotive supply chain." Supply Chain Management: An International Journal $7(2): 71-82$.

Camarinha-Matos, L. M. and C. Pantoja-Lima (2001). "Cooperation coordination in virtual enterprises." Journal of Intelligent Manufacturing 12: 133-150.

Christensen, L. C., T. R. Christiansen, et al. (1996). "Modeling and simulation in enterprise integration -- a framework and an application in the offshore oil industry." Concurrent Engineering Research and Applications Journal 4(3): 247259.

Crowston, K. (1997). "A coordination theory approach to organizational process design." Organizational Science 8(2): 157-175.

Daft, R. L. and R. H. Lengel (1986). "Organizational information requirements, media richness, and structural design." Management Science 32(5): 554-571. 
Doumeingts, G., B. Vallespir, et al. (1987). "Design methodology for advanced manufacturing systems." Computers in Industry 9: 271-296.

Flynn and Flynn (1999). "Information-processing alternatives for coping with manufacturing environmental complexity." Decision Sciences 30(4): 1021-1052.

Frohlich, M. T. and R. Westbrook (2001). "Arcs of integration: an international study of supply chain strategies." Journal of Operations Management 19: 185200.

Galbraith, J. R. (1977). Organizational Design. Reading, MA, Addison-Wesley.

Giachetti, R. (2004). "Enterprise Integration: An information integration perspective." International Journal of Production Research 42(6): 1147-1166.

Goodhue, D. (1996). "Understanding user evaluations of information systems." Management Science.

Joshi, K., Porth (2003). "Alignment of strategic priorities and performance: an integration of operations and strategic management perspectives." Journal of Operations Management 21(3): 353-369.

Kim, H. W. (2001). "Modeling inter- and intra-organizational coordination in electronic commerce deployments." Information Technology and Management 2: 335-354.

Koufteros, X. A., M. A. Vonderembse, et al. (2002). "Integrated product development practices and competitive capabilities: the effects of uncertainty, equivocality, and platform strategy." Journal of Operations Management 20: 331-355.

Kumar, K. and J. Van Hillesgersberg (2000). "ERP: Experiences and evolution." Communications of the ACM 43(4): 23-26.

Lawrence, P. R. and J. W. Lorsch (1967). Organization and Environment. Cambridge, MA, Harvard Graduate School of Business.

Lee, H., L. and S. Whang (1998). Information sharing in a supply chain, Graduate School of Business, Stanford University: 1-22.

Linthicum, D. S. (2000). Enterprise Application Integration. Reading, MA, AddisonWesley.

Malone, T. W. and K. Crowston (1994). "The interdisciplinary study of coordination." ACM Computing Surveys 26(1): 87-119.

Mintzberg, H. (1979). The structuring of organizations. Englewood Cliffs, NJ, Prentice-Hall.

Patankar, A. K. and S. Adiga (1995). "Enterprise integration modeling: a review of theory and practice." Computer Integrated Manufacturing Systems 8(1): 21-34.

Perrow, C. (1967). "A framework for the comparative analysis of organizations." American Sociological Review 32(2): 194-208.

Petrie, C. J. (1992). Enterprise integration modeling. Proceedings of the first international conference on enterprise integration, Cambridge, MA, MIT Press.

Rice, R. (1992). "Task analyzability, use of new media, and effectiveness: a multisite exploration of media richness." Organizational Science 3(4): 475-500.

Rosenzweig, E. D., A. V. Roth, et al. (2003). "The influence of an integration strategy on competitive capabilities and business performance." Journal of Operations Management.

Ruh, W. A, F. X. Maginnis, et al. (2000). Enterprise Application Integration: A Wiley Tech Brief. New York, NY, John Wiley \& Sons Inc. 
Themistocleous, M., Z. Irani, et al. (2001). "ERP and application integration: exploratory survey." Business Process Management Journal 7(3): 195-204.

Van de Ven, A. and A. Delbecq (1974). "A task contingent model of work-unit structure." Administrative Science Quarterly 19: 183-197.

Venkatraman, N. C. and J. C. Henderson (1993). "Continuous strategic alignment: exploiting information technology capabilities for competitive success." European Management Journal 11(2): 139-149.

Vernadat, F. (2002). "Enterprise Modeling and Integration (EMI): Current Status and Research Perspectives." Annual Reviews in Control 26: 15-25.

Vernadat, F. D. (1996). Enterprise modeling and integration. London, UK, Chapman and Hall.

Victor, B. and R. S. Blackburn (1987). "Determinants and consequences of task uncertainty: a laboratory and field investigation." Journal of Management Studies 24(4): 387-403.

Wacker, J. (1998). "A definition of theory: research guidelines for different theorybuilding research methods in operations research." Journal of Operations Management 16: 361-385.

Whang, S. (1995). "Coordination in operations: a taxonomy." Journal of Operations Management 12: 413-422.

Williams, T. J. (1994). "The Purdue reference architecture." Computers in Industry 24(2-3): 141-158.

Wybo, M. and D. Goodhue (1995). "Using interdependence as a predictor of data standards: theoretical and measurement issues." Information \& Management 29: 317-329. 